\title{
Pathophysiology and protective approaches of gut injury in critical illness
}

\author{
Chang Yeon Jung ${ }^{1}$, Jung Min Bae ${ }^{2}$ \\ ${ }^{1}$ Department of Surgery, Yeungnam University Hospital, Daegu, Korea \\ ${ }^{2}$ Department of Surgery, Yeungnam University College of Medicine, Daegu, Korea
}

Received: August 10, 2020

Revised: August 25, 2020

Accepted: August 31, 2020

Corresponding author:

Jung Min Bae

Department of Surgery, Yeungnam

University College of Medicine, 170

Hyeonchung-ro, Nam-gu, Daegu

42415, Korea

Tel: +82-53-620-3580

Fax: +82-53-624-1213

E-mail:netetern@naver.com
The gut is a complex organ that has played an important role in digestion, absorption, endocrine functions, and immunity. The gut mucosal barriers consist of the immunologic barrier and nonimmunologic barrier. During critical illnesses, the gut is susceptible to injury due to the induction of intestinal hyperpermeability. Gut hyperpermeability and barrier dysfunction may lead to systemic inflammatory response syndrome. Additionally, gut microbiota are altered during critical illnesses. The etiology of such microbiome alterations in critical illnesses is multifactorial. The interaction or systemic host defense modulation between distant organs and the gut microbiome is increasingly studied in disease research. No treatment modality exists to significantly enhance the gut epithelial integrity, permeability, or mucus layer in critically ill patients. However, multiple helpful approaches including clinical and preclinical strategies exist. Enteral nutrition is associated with an increased mucosal barrier in animal and human studies. The trophic effects of enteral nutrition might help to maintain the intestinal physiology, prevent atrophy of gut villi, reduce intestinal permeability, and protect against ischemia-reperfusion injury. The microbiome approach such as the use of probiotics, fecal microbial transplantation, and selective decontamination of the digestive tract has been suggested. However, its evidence does not have a high quality. To promote rapid hypertrophy of the small bowel, various factors have been reported, including the epidermal growth factor, membrane permeant inhibitor of myosin light chain kinase, mucus surrogate, pharmacologic vagus nerve agonist, immune-enhancing diet, and glucagon-like peptide-2 as preclinical strategies. However, the evidence remains unclear.

Keywords: Critical illness; Enteral nutrition; Intestines; Microbiota

\section{Introduction}

The gut is a complex organ that carries out important functions including digestion, absorption, endocrine regulation, and immunity. Microscopically, the gut wall consists of the serosa, muscularis propria, submucosa, and mucosa. The mucosa consists of the epithelium, lamina propria, crypt of Lieberkühn, and so on. The gut is covered by an epithelial layer with a surface area of $30 \mathrm{~m}^{2}$. The size of the surface area is similar in size to half a badminton court [1]. The epithelium plays a critical role as the first line of protection against pathogens and is important for the management of host homeostasis. Additionally, it is the central coordinator of mucosal immunity [2]. The lamina propria serves as a protective layer against microorganisms and is rich in immune cells. The gut is a continuously renewing organ with the majority of cells turning over within 1 week [3]. Several intestinal cells including absorptive enterocytes, mucus-producing goblet cells, hormone-producing enteroendocrine cells, and tuft cells are differentiated from intestinal stem cells residing near the base of crypt of Lieberkühn $[4,5]$.

As a result of constant microorganism exposure, the gut has sig-

Copyright (C) 2021 Yeungnam University College of Medicine

This is an Open Access article distributed under the terms of the Creative Commons Attribution Non-Commercial License (http://creativecommons.org/licenses/by-nc/4.0/) which permits unrestricted non-commercial use, distribution, and reproduction in any medium, provided the original work is properly cited. 
nificant immune function. Initially, several lymphoid cells in the lamina propria and Peyer's patch can detect pathogenic antigens. From these lymphoid cells, afferent lymphatics are drained from the mesenteric lymph nodes. Secretory immunoglobulins (Ig) including secretory IgA and immune cells can subsequently inhibit the pathogenicity of the antigen. Notably, secretory IgA inhibits the adherence of bacteria to the epithelium and prevents their colonization and multiplication. In addition, secretory IgA neutralizes bacterial toxins and viral activity and blocks the absorption of antigens from the gut [6]. These complex immune responses, cellular reactions, and immune cascades in the gut are called mucosal barriers [6].

These mucosal barriers consist of immunologic and nonimmunologic barriers. The immunologic barrier consists of secretory IgA and IgM lymphocytes. The nonimmunologic barrier consists of digestive enzymes, mucus, peristalsis, and gut flora [6]. In animal studies, sepsis can induce a decrease in the crypt proliferation and a diminution of the villus length $[7,8]$.

Mucus plays an important role in the mucosal defense by preventing the traversal of bacteria, digestive enzymes, and water-soluble toxic molecules into the mucosal surface [9]. In critical illnesses, the role of the mucus is compromised. Consequently, the damage to the mucus layer results in epithelial cell dysfunction. Gut ischemia/reperfusion leads to the loss of hydrophobicity of the mucus layer and altered intestinal permeability [9].

Under normal circumstances, approximately 40 trillion microorganisms reside within the gut. Gut microbiota can degrade dietary plant polysaccharides and proteins, to a small degree, by fermentation. The main end products of the fermentation are short-chain fatty acids (SCFAs) such as butyrate, acetate, and propionate. The SCFAs play an essential role in the maintenance of colonic integrity and metabolism. It has been shown that butyrate serves as the main energy source for colonocytes $[10,11]$. Several mechanisms regarding the maintenance of gut stability and homeostasis by microbiota have been proposed [12].

Preclinical studies have shown that the microbiome is essential for the protection against enteric and systemic pathogens through diverse mechanisms [13]. First, commensal microbiota can directly outcompete with intestinal pathogen or kill potential invaders by producing defensins and signaling molecules [14]. Second, microbiota are potent inducers of the immune system [15].

\section{Pathophysiology of gut injury}

During critical illnesses, it is commonly observed that the gut is susceptible to injury [16]. In the intensive care unit (ICU), approximately $50 \%$ of the patients experience enterocyte damage
[17]. The gut has been hypothesized to be the "motor" of critical illness $[18,19]$. This theory is based on the fact that critical illness induces intestinal hyperpermeability, leading to bacterial translocation and subsequent systemic infection. Gut damage causes gastrointestinal (GI) symptoms. The GI symptoms caused by gut damage occur in approximately $62 \%$ of the patients in ICUs [17].

In the 1970s, a gut mucosal damage grading system in the shock state was proposed [20]. Recently, a GI dysfunction grading system for critically ill patients was developed by the Working Group on Abdominal Problem (WGAP) of the European Society of Intensive Care Medicine (ESICM) [21]. Acute GI injury (AGI) grade I refers to the development of new GI symptoms, such as vomiting, gastric residual volume, diarrhea, GI bleeding, paralysis of the lower GI tract, or abnormal bowel sounds related to a known cause and perceived as transient (risk of developing GI dysfunction or failure). AGI grade II refers to a lack of improvement in these symptoms and no change in the general condition. This grade is an indication for intervention (for example, prokinetics, postpyloric feeding) to restore the GI function. AGI grade III refers to the persistence of GI symptoms or worsening of multiple organ dysfunction syndrome and lack of improvement in enteral feeding. This means that interventions cannot restore the GI function. Lastly, AGI grade IV refers to the presence of acute life-threatening GI problems [21] (Table 1). Studies regarding these grading systems have shown that critically ill patients with GI dysfunction have higher mortality rates than patients without AGI [22].

During critical illness, excessive or inadequate adaptive responses evoked by intensive stress can have negative effects on the gut motility, mucosal blood flow, and mucosal permeability [19,2326]. Gut hyperpermeability and barrier dysfunction may lead to a systemic inflammatory response syndrome, a clinical state that is also called "gut-derived sepsis" [27]. Sepsis induces a decrease in the crypt proliferation [7]. Critical illness induces gut mucosal hyperpermeability as early as 1 hour after the onset of sepsis and lasts at least 48 hours [3].

In addition, catecholamines administered to treat shock may lead to decreased microvascular perfusion in the gut [28]. This induces an increase of apoptosis and decrease of proliferation of small bowel mucosal cells, leading to the thinning of gut mucosa [29]. The resulting gut damage is exacerbated in the presence of chronic comorbidities such as cancer and chronic alcohol abuse $[30,31]$. Such injuries result in the impairment of the gut barrier and dysregulation of intestinal microbiota $[32,33]$. Therefore, small-intestinal mucosal integrity may be damaged in critically ill patients, leading to an increased intestinal permeability and intolerance to enteral nutrition [34].

Additionally, the gut microbiota is altered during conditions of 
Table 1. Definition, example, and management of acute gastrointestinal (GI) injury

\begin{tabular}{|c|c|c|c|}
\hline Grade & Definition & Example & Management \\
\hline I & $\begin{array}{l}\text { The function of the GI tract is partially impaired, } \\
\text { expressed as GI symptoms related to a known } \\
\text { cause, and perceived as transient }\end{array}$ & $\begin{array}{l}\text { Postoperative nausea and/or vomiting during } \\
\text { the first days after abdominal surgery, } \\
\text { postoperative absence of bowel sounds, } \\
\text { diminished bowel motility in the early phase } \\
\text { of shock }\end{array}$ & $\begin{array}{l}\text { Start or increase enteral feeding } \\
\text { Re-evaluate daily }\end{array}$ \\
\hline$\|$ & $\begin{array}{l}\text { The GI tract is not able to perform digestion and } \\
\text { absorption adequately to satisfy the nutrient } \\
\text { and fluid requirements of the body. There are } \\
\text { no changes in general condition of the patient } \\
\text { related to Gl problems }\end{array}$ & $\begin{array}{l}\text { Gastroparesis with high gastric residuals or } \\
\text { reflux, paralysis of the lower GI tract, diarrhea, } \\
\text { IAH grade I (IAP 12-15 mmHg), visible blood } \\
\text { in gastric content or stool. Feeding intolerance } \\
\text { is present if intake of at least } 20 \mathrm{kcal} / \mathrm{kg} \mathrm{BW} \\
\text { per day ( } 84 \mathrm{~kJ} / \mathrm{kg} \mathrm{BW} \text { per day) via enteral } \\
\text { route cannot be achieved within } 72 \mathrm{hr} \text { of } \\
\text { feeding attempt }\end{array}$ & $\begin{array}{l}\text { Start therapy according to the symptom } \\
\text { (e.g., prokinetics) } \\
\text { Measure IAP } \\
\text { Start minimal enteral feeding } \\
\text { Consider postpyloric feeding }\end{array}$ \\
\hline III & $\begin{array}{l}\text { Loss of GI function and restoration of GI } \\
\text { function is not achieved despite interventions, } \\
\text { and the general condition is not improving }\end{array}$ & $\begin{array}{l}\text { Despite treatment, feeding intolerance is } \\
\text { persisting: high gastric residuals, persisting GI } \\
\text { paralysis, occurrence or worsening of bowel } \\
\text { dilatation, progression of IAH to grade II (IAP } \\
15-20 \mathrm{mmHg}) \text {, low APP }(<60 \mathrm{mmHg}) \\
\text { Feeding intolerance is present and possibly } \\
\text { associated with persistence or worsening of } \\
\text { multiple organ dysfunction syndrome }\end{array}$ & $\begin{array}{l}\text { Search for undiagnosed abdominal pathology } \\
\text { Continue therapy according to the symptom } \\
\text { (e.g., prokinetics) } \\
\text { Treat IAH } \\
\text { Try (challenge) minimal feeding and start } \\
\text { parenteral nutrition }\end{array}$ \\
\hline IV & $\begin{array}{l}\text { Acute GI injury has progressed to become } \\
\text { directly and immediately life threatening, with } \\
\text { worsening of multiple organ dysfunction } \\
\text { syndrome and shock }\end{array}$ & $\begin{array}{l}\text { Bowel ischemia with necrosis, GI bleeding lead- } \\
\text { ing to hemorrhagic shock, Ogilvie's syndrome, } \\
\text { abdominal compartment syndrome requiring } \\
\text { decompression }\end{array}$ & $\begin{array}{l}\text { Requiring laparotomy or other emergency } \\
\text { interventions (e.g., colonoscopy for colonic } \\
\text { decompression) }\end{array}$ \\
\hline
\end{tabular}

Based on Reintam Blaser et al. [21].

$I A H$, intraabdominal hypertension; IAP, intraabdominal pressure; BW, body weight; $k J$, kilojoules; APP, abdominal perfusion pressure.

critical illness. Within hours of the onset of a critical illness, the normal microbiota can convert to a disease-promoting pathobiome [35]. The diversity of a microbiome is significantly impaired during critical illness [3]. The etiology of such microbiome alteration in critical illness is multifactorial. These factors include an isolated host milieu, ancestral or newly expressed genes, numerous medical drugs, nutrients, and nutrition support routes [3]. In injured gut microbiota, diet is the key to shaping the ecosystem of the gut microbiome, which is important for host metabolism [36]. In critically ill patients, the microbiota can be severely altered to become unstable [37].

Critical illness leads to multiple changes to the microbiome, including the loss of diversity and overgrowth of pathogenic bacteria [38]. Distortion of the composition and diversity of the gut microbiome is defined as "dysbiosis." Recently, it has been hypothesized that gut microbiome injury can cause distant organ injury. Microbiota-derived components such as pathogen-associated molecular patterns and metabolites derived from the gut can reach the circulatory system and interact at a systemic level to influence the immune homeostasis [39,40].

Such interactions or systemic host defense modulations between a distant organ and the gut microbiome is increasingly studied in disease research. Subsequently, the theory of gut-organ axes (gut-lung axis, gut-brain axis, gut-kidney axis, and gut-liver axis) has been developed [40].

\section{Gut-lung axis}

Evidence regarding the gut-lung axis emerged 20 years ago from rat model studies of trauma and hemorrhagic shock [41]. It was demonstrated that during trauma and hemorrhagic shock, gut-derived compounds translocated through the mesenteric lymph, causing distal lung injury [42].

\section{Gut-brain axis}

Recent research has shown that an extensive crosstalk between the gut microbiome and the brain through neuropeptides or endocrine processes, immune system signaling, and nerve signaling. The gut microbiome has been suggested to play a role in the cognitive function and behavior $[43,44]$.

\section{Gut-kidney axis}

Recent murine studies have shown that therapy with SCFAs including acetate, propionate, and butyrate has protective effects in an ischemia/reperfusion model of acute kidney injury [45]. However, another study showed that the renal resident macrophages in the normal gut microbiome were sensitive to renal ischemia/ reperfusion injury, resulting in initiation of inflammation and subsequent nephropathy after renal injury.

In contrast, the renal resident macrophages in a depleted gut microbiome are less sensitive to renal ischemia/reperfusion injury, resulting in an increased protection against renal ischemia/reperfu- 
sion injury [46].

\section{Gut-liver axis}

The liver may also be injured when the gut is injured. The liver is exposed to bacterial components and their metabolites via portal flow from the gut [47]. Therefore, the maintenance of gut mucosal integrity during critical illness is very important.

\section{Protection of gut and several approaches to enhancing gut integrity and permeability}

No treatment modality exists to significantly enhance the gut epithelial integrity, permeability, or mucus layer in critically ill patients. However, multiple helpful approaches including clinical and preclinical strategies exist. In animal studies, enteral nutrition can increase the blood flow in the gut during a "postprandial hyperemic response." This may preserve the gut integrity and prevent gut-derived complications $[48,49]$.

Enteral feed is associated with an increased mucosal mass and villus height in animal and human studies [50,51]. The trophic effects of enteral nutrition may help to maintain the intestinal physiology, prevent atrophy of gut villi, reduce intestinal permeability, protect against ischemia-reperfusion injury by stimulating intestinal perfusion, and preserve the gut immunity by affecting gut-associated lymphoid tissue [52]. However, the initiation of enteral nutrition should be started carefully considering enteral nutrition-derived complication, gut function, and contractility (e.g., ESICM WGAP recommendations) [53].

Several researchers have proposed that delayed trophic feeding (after 72 hours from intensive stress) is the optimal choice for critically ill patients with AGI, although this lacks evidence. As a protective strategy, trophic feeding may reduce the gut burden, help to maintain the intestinal physiology, prevent mucosal atrophy, and maintain the gut integrity in critically ill patients [54]. However, frequently providing enteral nutrition might have several complications, including vomiting, diarrhea, GI bleeding, aspiration pneumonia, refeeding syndrome, and gut ischemia $[55,56]$. In critically ill patients, enteral nutrition-related complications have been frequently observed [57].
According to surviving sepsis guidelines, enteral nutrition is recommended as soon as possible [58]. However, the tool for identifying patients who are likely to benefit from enteral nutrition among those who are critically ill with AGI and nutrition support protocol for decreasing enteral nutrition-related complications show poor performances [53].

The microbiome approach such as the use of probiotics, fecal microbial transplantation (FMT), and selective decontamination of the digestive tract has been suggested [3]. However, its evidence is not of high quality. Theoretically, the microbiome treatment will increase the number of "health-promoting" bacteria and decrease that of the "disease-promoting" bacteria. A microbiome treatment involves administering probiotics. Although significant evidence is not yet obtained, meta-analyses have demonstrated that ventilator-associated pneumonia improves following the administration of probiotics [59]. FMT involves the administration of an entire microbiome from a healthy donor and is considered for Clostridium difficile infections. Critically ill patients frequently receive antibiotics, and their microbiome is expected to alter due to antibiotic therapy. Therefore, FMT may be considered during critical illnesses [3]. However, the current evidence about microbiota-related therapies in critical illness remains unclear and limited to preclinical settings [40].

To promote rapid hypertrophy of the small bowel, several compounds have been reported, including epidermal growth factor, membrane permeant inhibitor of myosin light chain kinase, mucus surrogate, pharmacologic vagus nerve agonist, immune-enhancing diet, and glucagon-like peptide-2 as preclinical strategies [60-64]. However, the evidence remains unclear. Immune-enhancing nutrients (e.g., glutamine, alanine) can stimulate the enteric blood flow, maintain the mucosal barrier function by preserving tight-junction integrity, and induce the production and release of mucosal Ig and critical endogenous growth factors [6] (Table 2).

\section{Conclusion}

In critical illness, the gut is susceptible to injury due to multifactorial causes. No treatment modality exists to significantly enhance the gut barrier. Although current evidence is not of high quality, the

Table 2. Various materials to improve gut barrier and immunity

Material

Epidermal growth factor [60]

Glucagon-like peptide-2 [61]

Membrane permeant inhibitor of myosin light chain kinase [62]

Mucus surrogate [63]

Pharmacologic vagus nerve agonist [64]

\section{Effect}

Improve gut apoptosis, proliferation, and permeability

Promote sufficient gut hypertrophy

Improve intestinal permeability

Prevent trauma/hemorrhagic shock-induced gut injury

Attenuate toxic mesenteric lymph-induced lung injury 
enteral feed is associated with an increased gut barrier. Therefore microbiome treatment has been suggested. Additionally, in our review of the various studies, we concisely compiled the most up-todate knowledge, on gut injury mechanisms and protection of the gut during critical illness. Further investigations should be performed with respect to the treatment of gut damage during critical illness.

\section{Acknowledgments}

\section{Conflicts of interest}

No potential conflicts of interest relevant to this article were reported.

\section{Author contributions}

Conceptualization: CYJ, JMB; Investigation and Resources: CYJ; Writing-original draft: CYJ, JMB; Writing-review \& editing: JMB.

\section{Previous presentations}

The summary of this review was presented in the Acute and Critical Care Conference 2020 and the 40th Annual Meeting of Korean Society of Critical Care Medicine.

\section{ORCID}

Chang Yeon Jung, https://orcid.org/0000-0002-4681-0936

Jung Min Bae, https://orcid.org/0000-0003-0923-763X

\section{References}

1. Helander HF, Fändriks L. Surface area of the digestive tract: revisited. Scand J Gastroenterol 2014;49:681-9.

2. Allaire JM, Crowley SM, Law HT, Chang SY, Ko HJ, Vallance BA. The intestinal epithelium: central coordinator of mucosal immunity. Trends Immunol 2018;39:677-96.

3. Otani S, Coopersmith CM. Gut integrity in critical illness. J Intensive Care 2019; 7:17.

4. Knoop KA, Newberry RD. Goblet cells: multifaceted players in immunity at mucosal surfaces. Mucosal Immunol 2018;11: 1551-7.

5. Gerbe F, Sidot E, Smyth DJ, Ohmoto M, Matsumoto I, Dardalhon $\mathrm{V}$, et al. Intestinal epithelial tuft cells initiate type 2 mucosal immunity to helminth parasites. Nature 2016;529:226-30.

6. Townsend CM, Sabiston DC, Beauchamp RD, Evers BM, Mattox KL. Sabiston textbook of surgery: the biological basis of modern surgical practice. 20th ed. Philadelphia (PA): Elsevier; 2017.

7. Coopersmith CM, Stromberg PE, Davis CG, Dunne WM,
Amiot DM 2nd, Karl IE, et al. Sepsis from Pseudomonas aeruginosa pneumonia decreases intestinal proliferation and induces gut epithelial cell cycle arrest. Crit Care Med 2003;31:1630 7.

8. Meng M, Klingensmith NJ, Liang Z, Lyons JD, Fay KT, Chen CW, et al. Regulators of intestinal epithelial migration in sepsis. Shock 2019;51:88-96.

9. Qin X, Caputo FJ, Xu DZ, Deitch EA. Hydrophobicity of mucosal surface and its relationship to gut barrier function. Shock 2008;29:372-6.

10. Cook SI, Sellin JH. Review article: short chain fatty acids in health and disease. Aliment Pharmacol Ther 1998;12:499-507.

11. Morrison DJ, Preston T. Formation of short chain fatty acids by the gut microbiota and their impact on human metabolism. Gut Microbes 2016;7:189-200.

12. Dickson RP. The microbiome and critical illness. Lancet Respir Med 2016;4:59-72.

13. Haak BW, Levi M, Wiersinga WJ. Microbiota-targeted therapies on the intensive care unit. Curr Opin Crit Care 2017;23:16774.

14. Klingensmith NJ, Coopersmith CM. The gut as the motor of multiple organ dysfunction in critical illness. Crit Care Clin 2016;32:203-12.

15. Pamer EG. Resurrecting the intestinal microbiota to combat antibiotic-resistant pathogens. Science 2016;352:535-8.

16. Reintam A, Parm P, Kitus R, Kern H, Starkopf J. Gastrointestinal symptoms in intensive care patients. Acta Anaesthesiol Scand 2009;53:318-24.

17. Piton G, Belon F, Cypriani B, Regnard J, Puyraveau M, Manzon $\mathrm{C}$, et al. Enterocyte damage in critically ill patients is associated with shock condition and 28-day mortality. Crit Care Med 2013;41:2169-76.

18. Clark JA, Coopersmith CM. Intestinal crosstalk: a new paradigm for understanding the gut as the "motor" of critical illness. Shock 2007;28:384-93.

19. Meng M, Klingensmith NJ, Coopersmith CM. New insights into the gut as the driver of critical illness and organ failure. Curr Opin Crit Care 2017;23:143-8.

20. Chiu CJ, McArdle AH, Brown R, Scott HJ, Gurd FN. Intestinal mucosal lesion in low-flow states. I. A morphological, hemodynamic, and metabolic reappraisal. Arch Surg 1970;101:478-83.

21. Reintam Blaser A, Malbrain ML, Starkopf J, Fruhwald S, Jakob SM, de Waele J, et al. Gastrointestinal function in intensive care patients: terminology, definitions and management. Recommendations of the ESICM Working Group on Abdominal Problems. Intensive Care Med 2012;38:384-94.

22. Li H, Zhang D, Wang Y, Zhao S. Association between acute gas- 
trointestinal injury grading system and disease severity and prognosis in critically ill patients: a multicenter, prospective, observational study in China.J Crit Care 2016;36:24-8.

23. Stratakis CA, Chrousos GP. Neuroendocrinology and pathophysiology of the stress system. Ann N Y Acad Sci 1995;771:118.

24. Gué M, Peeters T, Depoortere I, Vantrappen G, Buéno L. Stress-induced changes in gastric emptying, postprandial motility, and plasma gut hormone levels in dogs. Gastroenterology 1989;97:1101-7.

25. Richardson RS, Norton LW, Sales JE, Eiseman B. Gastric blood flow in endotoxin-induced stress ulcer. Arch Surg 1973;106: $191-5$.

26. Wallon C, Yang PC, Keita AV, Ericson AC, McKay DM, Sherman PM, et al. Corticotropin-releasing hormone (CRH) regulates macromolecular permeability via mast cells in normal human colonic biopsies in vitro. Gut 2008;57:50-8.

27. Deitch EA. Gut-origin sepsis: evolution of a concept. Surgeon 2012;10:350-6.

28. Krejci V, Hiltebrand LB, Sigurdsson GH. Effects of epinephrine, norepinephrine, and phenylephrine on microcirculatory blood flow in the gastrointestinal tract in sepsis. Crit Care Med 2006;34:1456-63.

29. Chung DH, Evers BM, Townsend CM Jr, Huang KF, Shimoda I, Herndon DN, et al. Burn-induced transcriptional regulation of small intestinal ornithine decarboxylase. Am J Surg 1992;163:157-62.

30. Klingensmith NJ, Fay KT, Lyons JD, Chen CW, Otani S, Liang $\mathrm{Z}$, et al. Chronic alcohol ingestion worsens survival and alters gut epithelial apoptosis and CD8+ T cell function after pseudomonas aeruginosa pneumonia-induced sepsis. Shock 2019;51: 453-63.

31. Fox AC, Robertson CM, Belt B, Clark AT, Chang KC, Leathersich AM, et al. Cancer causes increased mortality and is associated with altered apoptosis in murine sepsis. Crit Care Med 2010;38:886-93.

32. Li H, Chen Y, Huo F, Wang Y, Zhang D. Association between acute gastrointestinal injury and biomarkers of intestinal barrier function in critically ill patients. BMC Gastroenterol 2017;17:45

33. Lankelma JM, van Vught LA, Belzer C, Schultz MJ, van der Poll T, de Vos WM, et al. Critically ill patients demonstrate large interpersonal variation in intestinal microbiota dysregulation: a pilot study. Intensive Care Med 2017;43:59-68.

34. Burgstad CM, Besanko LK, Deane AM, Nguyen NQ, Saadat-Gilani K, Davidson G, et al. Sucrose malabsorption and impaired mucosal integrity in enterally fed critically ill patients: a prospective cohort observational study. Crit Care Med 2013; 41:1221-8.

35. Alverdy JC, Krezalek MA. Collapse of the microbiome, emergence of the pathobiome, and the immunopathology of sepsis. Crit Care Med 2017;45:337-47.

36. Sonnenburg JL, Bäckhed F. Diet-microbiota interactions as moderators of human metabolism. Nature 2016;535:56-64.

37. Wischmeyer PE, McDonald D, Knight R. Role of the microbiome, probiotics, and 'dysbiosis therapy' in critical illness. Curr Opin Crit Care 2016;22:347-53.

38. McDonald D, Ackermann G, Khailova L, Baird C, Heyland D, Kozar R, et al. Extreme dysbiosis of the microbiome in critical illness. mSphere 2016;1:e0199-16.

39. Levy M, Blacher E, Elinav E. Microbiome, metabolites and host immunity. Curr Opin Microbiol 2017;35:8-15.

40. Jacobs MC, Haak BW, Hugenholtz F, Wiersinga WJ. Gut microbiota and host defense in critical illness. Curr Opin Crit Care 2017;23:257-63.

41. Magnotti LJ, Upperman JS, Xu DZ, Lu Q, Deitch EA. Gut-derived mesenteric lymph but not portal blood increases endothelial cell permeability and promotes lung injury after hemorrhagic shock. Ann Surg 1998;228:518-27.

42. Deitch EA, Xu DZ, Lu Q. Gut lymph hypothesis of early shock and trauma-induced multiple organ dysfunction syndrome: a new look at gut origin sepsis. J Organ Dysfunct 2009;2:70-9.

43. Carabotti M, Scirocco A, Maselli MA, Severi C. The gut-brain axis: interactions between enteric microbiota, central and enteric nervous systems. Ann Gastroenterol 2015;28:203-9.

44. Foster JA, McVey Neufeld KA. Gut-brain axis: how the microbiome influences anxiety and depression. Trends Neurosci 2013;36:305-12.

45. Andrade-Oliveira V, Amano MT, Correa-Costa M, Castoldi A, Felizardo RJ, de Almeida DC, et al. Gut bacteria products prevent AKI induced by ischemia-reperfusion. J Am Soc Nephrol 2015;26:1877-88.

46. Emal D, Rampanelli E, Stroo I, Butter LM, Teske GJ, Claessen $\mathrm{N}$, et al. Depletion of gut microbiota protects against renal ischemia-reperfusion injury.J Am Soc Nephrol 2017;28:1450-61.

47. Tilg H, Cani PD, Mayer EA. Gut microbiome and liver diseases. Gut 2016;65:2035-44.

48. Kazamias P, Kotzampassi K, Koufogiannis D, Eleftheriadis E. Influence of enteral nutrition-induced splanchnic hyperemia on the septic origin of splanchnic ischemia. World J Surg 1998; 22:6-11.

49. Purcell PN, Davis KJr, Branson RD, Johnson DJ. Continuous duodenal feeding restores gut blood flow and increases gut oxygen utilization during PEEP ventilation for lung injury. Am J 
Surg 1993;165:188-93.

50. Alverdy JC, Aoys E, Moss GS. Total parenteral nutrition promotes bacterial translocation from the gut. Surgery 1988;104:185-90.

51. Groos S, Hunefeld G, Luciano L. Parenteral versus enteral nutrition: morphological changes in human adult intestinal mucosa. J Submicrosc Cytol Pathol 1996;28:61-74.

52. Schmidt H, Martindale R. The gastrointestinal tract in critical illness. Curr Opin Clin Nutr Metab Care 2001;4:547-51.

53. Zhang D, Li H, Li Y, Qu L. Gut rest strategy and trophic feeding in the acute phase of critical illness with acute gastrointestinal injury. Nutr Res Rev 2019;32:176-82.

54. McClave SA, Taylor BE, Martindale RG, Warren MM, Johnson $\mathrm{DR}$, Braunschweig C, et al. Guidelines for the provision and assessment of nutrition support therapy in the adult critically ill patient: Society of Critical Care Medicine (SCCM) and American Society for Parenteral and Enteral Nutrition (A.S.P.E.N.). JPEN J Parenter Enteral Nutr 2016;40:159-211.

55. Boullata JI, Carrera AL, Harvey L, Escuro AA, Hudson L, Mays A, et al. ASPEN safe practices for enteral nutrition therapy. JPEN J Parenter Enteral Nutr 2017;41:15-103.

56. Seol EM, Kwon KS, Kim JG, Kim JT, Kim J, Moon SM, et al. Nutritional therapy related complications in hospitalized adult patients: a Korean multicenter trial. J Clin Nutr 2019;11:12-22.

57. Reignier J, Darmon M, Sonneville R, Borel AL, Garrouste-Orgeas M, Ruckly S, et al. Impact of early nutrition and feeding route on outcomes of mechanically ventilated patients with shock: a post hoc marginal structural model study. Intensive Care Med 2015;41:875-86.
58. Dellinger RP, Levy MM, Rhodes A, Annane D, Gerlach H, Opal SM, et al. Surviving Sepsis Campaign: international guidelines for management of severe sepsis and septic shock, 2012. Intensive Care Med 2013;39:165-228.

59. Weng H, Li JG, Mao Z, Feng Y, Wang CY, Ren XQ, et al. Probiotics for preventing ventilator-associated pneumonia in mechanically ventilated patients: a meta-analysis with trial sequential analysis. Front Pharmacol 2017;8:717.

60. Klingensmith NJ, Yoseph BP, Liang Z, Lyons JD, Burd EM, Margoles LM, et al. Epidermal growth factor improves intestinal integrity and survival in murine sepsis following chronic alcohol ingestion. Shock 2017;47:184-92.

61. Townsend CM, Sabiston DC. Sabiston textbook of surgery: the biological basis of modern surgical practice. 16th ed. Philadelphia (PA): WB Saunders; 2001.

62. Zahs A, Bird MD, Ramirez L, Turner JR, Choudhry MA, Kovacs EJ, et al. Inhibition of long myosin light-chain kinase activation alleviates intestinal damage after binge ethanol exposure and burn injury. Am J Physiol Gastrointest Liver Physiol 2012; 303:G705-12.

63. Fishman JE, Sheth SU, Levy G, Alli V, Lu Q, Xu D, et al. Intraluminal nonbacterial intestinal components control gut and lung injury after trauma hemorrhagic shock. Ann Surg 2014; 260:1112-20.

64. Langness S, Costantini TW, Morishita K, Eliceiri BP, Coimbra R. Modulating the biologic activity of mesenteric lymph after traumatic shock decreases systemic inflammation and end organ injury. PLoS One 2016;11:e168322. 